\title{
MICROENCAPSULAÇÃO DO ÓLEO ESSENCIAL DE LARANJA POR SPRAY DRYING E ANÁLISE DA SUA ESTABILIDADE OXIDATIVA
}

\author{
M. MORETTI ${ }^{1}$, J. J. FIORI $^{1}$ \\ ${ }^{1}$ Centro Universitário Padre Anchieta, Jundiaí, SP \\ E-mail para contato: juliano.fiori@anchieta.br
}

\begin{abstract}
RESUMO - Na microencapsulação por spray drying, partículas microscópicas são secas e revestidas por um agente encapsulante. Neste trabalho, a estabilidade oxidativa foi realizada por comparação do aroma líquido com o microencapsulado por 75 dias em temperatura ambiente (A) e estufa a $40{ }^{\circ} \mathrm{C}(\mathrm{E})$. Foram feitas análises de densidade (D) e índice de refração (IR) da fase oleosa, $\mathrm{pH}$ e umidade (U) do pó, a cada quinzena. Também foi feito o perfil cromatográfico. O IR foi de 1,47 e a $\mathrm{D}$ foi de $0,855 \mathrm{~g} / \mathrm{mL}$, ocorrendo ligeira variação ao longo do teste. $\mathrm{O} \mathrm{pH}$ iniciou em 3,85 e terminou em 4,05, variando pouco entre A e E. A U teve o valor de 3,66\% no início dos testes e terminou em 3,30\% (E) e 4,44\% (A). A análise sensorial foi feita com um aromista e um leigo para diversos descritores em escala de 1 a 10, indicando a mudança de qualidade negativa. $\mathrm{O}$ cromatograma indicou pouca variação nos terpenos, porém a oxidação no aroma líquido foi notada pelos provadores, indicando que o processo foi positivo para a estabilidade do aroma.
\end{abstract}

\section{INTRODUÇÃO}

O óleo essencial de laranja, dentre os óleos essenciais, é o que possui o maior índice de terpenos, que é uma diversificada classe de substâncias de origem vegetal. Os principais componentes químicos existentes no produto são: d-limoneno, mirceno, $\alpha$-pineno, sabieno, decanal, linalol, octanol e $\alpha$-terpineol. $\mathrm{O}$ óleo apresenta uma coloração amarelada, aspecto de um líquido claro e odor característico, além de ser extremamente instável, podendo oxidar-se muito facilmente. Os compostos aromatizantes são quimicamente instáveis e se oxidam com facilidade na presença do ar, luz e umidade. Os compostos resultantes dessa oxidação contribuem para a rancificação dos produtos elaborados com o óleo de laranja (Jun-xia et al., 2011; Aburto et al., 1998).

Atualmente, existem várias tecnologias disponíveis para realizar a microencapsulação de partículas, entre elas podem ser citadas: a atomização; a extrusão; o leito fluidizado; a cocristalização; a liofilização; a secagem em tambor; a inclusão molecular; além da inclusão em lipossomas. A técnica mais comumente utilizada para a retenção do óleo essencial em microcápsulas na forma seca é o spray drying, na qual as partículas atomizadas secam rapidamente, mantendo os constituintes voláteis aromatizantes no interior dos glóbulos formados - ou microcápsulas. A microencapsulação é uma tecnologia que permite revestir partículas sólidas ou líquidas com um invólucro, protegendo compostos quimicamente instáveis da ação de agentes externos, tais como ar, umidade e luz (Liu et al., 2012; Castelo Branco, 2010; Ahn et al., 2008). 
A secagem por atomização consiste no contato, dentro de uma câmara fechada, entre uma corrente de ar quente e uma solução líquida transformada em gotas muito pequenas. Devido a alta diferença de temperatura e de concentração, ocorre um processo simultâneo de transferência de calor e massa, retirando material volátil das gotas. $\mathrm{O}$ tempo de contato, por ser diminuto, favorece a mínima deterioração do produto. As condições de processo influenciam grandemente nas características do produto final.

Tonon e colaboradores (2011) investigaram a microencapsulação de óleo de linhaça em um minissecador empregando goma arábica como material de parede. Por um delineamento composto central, com três variáveis independentes: temperatura do ar se secagem (138-202 $\left.{ }^{\circ} \mathrm{C}\right)$, conteúdo de sólidos totais (10-30 \% em massa) e concentração de óleo com relação aos sólidos totais (10-30 \% em massa), os autores estudaram as respostas: eficiência de encapsulação, oxidação lipídica e densidade do pó, além da morfologia do pó e distribuição do tamanho de partículas. Os resultados obtidos indicaram que um maior teor de sólidos e uma concentração de óleo menor levaram a uma maior eficiência de encapsulação e menor oxidação lipídica. O aumento da temperatura de secagem resultou em maior oxidação. A densidade do pó aumentou para maior teor de sólidos e baixa temperatura do ar de entrada.

Em um estudo relacionado, Frascareli et al. (2012) avaliaram a microencapsulação de óleo de café, utilizando as mesmas variáveis independentes do estudo de Tonon et al. (2011), porém em níveis adequados ao tipo de produto. Segundo os autores, a eficiência de encapsulação e a retenção de óleo foram influenciados negativamente pela concentração de óleo e temperatura do ar, e positivamente afetados pelo teor de sólidos totais, o que poderia estar relacionado com a viscosidade e o tamanho das gotas da emulsão, confirmando teorias propostas por Tonon et al. (2011). O pó com melhores condições de encapsulação e a fase oleosa líquida foram avaliadas quanto à estabilidade oxidativa a $25^{\circ} \mathrm{C}$ e $60{ }^{\circ} \mathrm{C}$, indicando o pó ser estável durante a armazenagem a menor temperatura, mas não a $60{ }^{\circ} \mathrm{C}$. Em contrapartida, em qualquer das duas temperaturas, o óleo puro apresentou maior oxidação de lipídios que o encapsulado, confirmando o efeito protetor de microencapsulação.

Tendo em vista a aplicabilidade dos óleos essenciais na indústria alimentícia, é importante discutir e analisar a utilização do método de secagem por atomização na microencapsulação do óleo essencial de laranja, pois, por ser um óleo cítrico de alta volatilidade, torna-se mais difícil manter as características e o aroma em veículos líquidos, justificando-se, assim, o desenvolvimento deste trabalho.

O objetivo deste trabalho foi apresentar um estudo de vida útil comparativo a respeito de oxidação e de perdas aromáticas de um aroma de laranja microencapsulado e de um aroma de laranja em veículo líquido, por meio de determinações físico-químicas nas amostras, avaliação do perfil sensorial descritivo e corridas cromatográficas.

\section{MATERIAL E MÉTODOS}

Neste estudo, foi feita a comparação de amostras da fase oleosa (aroma líquido) e de amostras de produto final (pó microencapsulado). As amostras (líquido e pó microencapsulado) foram separadas em porções e acondicionadas em recipientes de vidro 
âmbar, com tampa rosqueada, com o intuito de evitar maiores exposições ao oxigênio e à luz, potenciais agentes aceleradores de oxidação.

As amostras de fase oleosa foram dividas em três porções. O primeiro frasco foi analisado no início do estudo e posteriormente descartado, devido à violação. A análise consistiu em uma avaliação físico-química e sensorial do material. $\mathrm{O}$ segundo frasco foi deixado em estufa à $40^{\circ} \mathrm{C}$ e o terceiro, à temperatura ambiente, $25^{\circ} \mathrm{C}$. Após 75 dias, ambas as amostras sofreram as mesmas análises sofridas pela primeira amostra e foram posteriormente descartadas.

Parte do aroma oleoso foi divida em onze porções que passaram pelo processo de microencapsulação com maltodextrina em spray dryer piloto, sendo posteriormente envasadas em frascos. As onze porções tiveram um destino semelhante às da fase oleosa não microencapsulada: uma amostra foi analisada no início do estudo e descartada; e dois grupos de cinco foram deixados em estufa e à temperatura ambiente, sendo preservadas as mesmas condições da amostra líquida. A cada quinze dias uma amostra de cada destino foi avaliada, durante um período de 75 dias. Após as análises, as amostras foram descartadas.

As análises sensoriais foram feitas por um aromista especializado em cítricos e por uma pessoa inexperiente (leigo), com o objetivo de comparar em qual período de vida útil do aroma o consumidor leigo conseguiria identificar o início e a manutenção dos processos oxidativos. A qualificação sensorial dos descritores sensoriais das amostras foi um valor no intervalo de um (1) a dez (10), de acordo com a intensidade constatada na análise. Para descritores com intensidade não observada, foi adotado um sinal indicativo de ausência, dada pelo caractere $\mathrm{X}$.

Os descritores da laranja analisados na análise sensorial das amostras foram: Tangerina: (nota associada à fruta "mandarina"), Laranja Verde (nota associada à laranja verde frutal), Laranja Suco (nota associada a suco de laranja fruta natural levemente cozido), Laranja Fresca (nota associada à fruta fresca com perfil de suco de laranja tipo "pêra"), Albedo (nota associada à casca da laranja na parte interna "albedo"), Ácido (nota associada à acidez da laranja), Frutal (nota associada a frutas), Laranja Madura/Cozida (nota associada à fruta madura), Floral (nota associada a flores e notas florais frutais), Cítrico (nota associada à mistura de limão e laranja "cítricos"), Laranja Oxidada (nota associada à oxidação de cítricos - laranja, limão, etc), Aldeído Casca (nota associada a características de aldeídos em notas cítricas de casca).

As amostras para análise sensorial foram preparadas da seguinte maneira: (a) Diluição para análise sensorial da amostra líquida: $50 \mathrm{~g}$ de álcool etílico para $0,5 \mathrm{~g}$ de aroma líquido (solução 1); $100 \mathrm{~g}$ de água para $0,5 \mathrm{~g}$ de solução, $1,2 \mathrm{~g}$ ácido cítrico $50 \%$ e $5 \mathrm{~g}$ de açúcar cristal. (b) Diluição para análise sensorial da amostra pó: $100 \mathrm{~g}$ de água para $0,2 \mathrm{~g}$ de aroma pó, $2 \mathrm{~g}$ ácido cítrico $50 \%$ e $5 \mathrm{~g}$ de açúcar cristal. O ácido cítrico e o açúcar foram utilizados para potencializar o impacto do aroma.

Para análise da densidade da fase oleosa, foi utilizado o densímetro digital modelo - DE 40 - Mettler Toledo, com precisão de até 0,0001. O índice de refração da fase oleosa foi determinado por refratômetro RE - 40 - Mettler Toledo com precisão de até 0,0001. Para a análise da umidade do pó, foi utilizado o analisador de umidade de halogênio HB-43 - 
Mettler Toledo, por secagem infravermelha. O potencial hidrogeniônico (pH) do pó foi medido em pHmetro DL-50 - Eletrodo DG111-SC - Mettler Toledo, com o uso de uma solução a $1 \%$. A análise cromatográfica foi realizada apenas na fase oleosa, em cromatógrafo gasoso com detector de chama. A fase final (pó) não apresentou uma preparação adequada, não se solubilizando eficientemente em acetona, impossibilitando o procedimento no equipamento.

\section{RESULTADOS E DISCUSSÃO}

As Tabelas 1, 2 e 3 representam os resultados obtidos pela análise sensorial das amostras de fase oleosa e do produto final (pó microencapsulado). Os valores indicados por cada avaliador estão dispostos separadamente nas tabelas, de modo que fica evidente sua comparação.

Tabela 1 - Comparativo dos descritores das análises da fase oleosa

\begin{tabular}{lcccccc}
\hline \multicolumn{1}{c}{ Temperatura } & \multicolumn{2}{c}{ Amb. - Início } & \multicolumn{2}{c}{ Amb. -75 d. } & \multicolumn{2}{c}{ Est. -75 d. } \\
\hline \multicolumn{1}{c}{ Descritores } & $\mathrm{A}$ & $\mathrm{L}$ & $\mathrm{A}$ & $\mathrm{L}$ & $\mathrm{A}$ & $\mathrm{L}$ \\
\hline Tangerina & $\mathrm{X}$ & $\mathrm{X}$ & 3 & 3 & 3 & 3 \\
Laranja Verde & $\mathrm{X}$ & $\mathrm{X}$ & 3 & 2 & 3 & 2 \\
Laranja Suco & 7 & 7 & 5 & 2 & 4 & 2 \\
Laranja Fresca & 7 & 6 & 5 & 2 & 3 & 2 \\
Albedo & 4 & 4 & 4 & 4 & 5 & 5 \\
Ácido & $\mathrm{X}$ & $\mathrm{X}$ & 3 & 4 & 3 & 3 \\
Frutal & 5 & 5 & 4 & 4 & 4 & 4 \\
Laranja Madura/Cozida & 4 & 5 & 3 & 5 & 4 & 4 \\
Floral & 3 & 2 & 3 & 2 & 3 & 3 \\
Cítrico & 8 & 8 & 5 & 6 & 5 & 5 \\
Laranja Oxidada & $\mathrm{X}$ & $\mathrm{X}$ & 3 & 4 & 5 & 7 \\
Aldeído Casca & 4 & 3 & 3 & 4 & 4 & 5 \\
\hline
\end{tabular}

Legenda: Amb. $=$ ambiente, Est. $=$ estufa, $\mathrm{A}=$ aromista, $\mathrm{L}=$ leigo.

Pelos dados apresentados nas Tabelas 1, 2 e 3, é possível observar variações nas marcas obtidas por um mesmo descritor durante o período do estudo, tanto na amostra de fase oleosa, quanto na amostra de pó. Tais alterações apontam perdas aromáticas de alguns atributos e aparecimento de aromas indesejados, decorrentes de modificações causadas pela oxidação da amostra. Em geral, a fase oleosa sofreu uma maior mudanç aromática durante o período do experimento. Destacam-se os descritores Ácido, Floral e Cítrico, os quais, para o pó, começam a ser percebidos pelos provadores após 45 dias de armazenamento. $\mathrm{O}$ atributo Cítrico não foi apontado para a fase oleosa no início do teste. Essas características indicam alterações negativas nos preparados, pois descaracterizam a amostra inicial. Para o descritor Laranja Oxidada, sendo este o que mais indica a oxidação, nota-se que a partir de 15 dias de armazenamento dá-se início a sua percepção, sendo potencializada ao longo do período de estudo. A pouca quantidade de amostra de fase oleosa disponível para este estudo não permitiu a análise a cada quinzena, tendo apenas o início e o final do teste como comparação. 
Tabela 2 - Comparativo dos descritores das análises do pó, primeiros 30 dias

\begin{tabular}{lccccccccccc}
\hline \multicolumn{1}{c}{ Temperatura } & \multicolumn{2}{c}{ Amb. - Início } & \multicolumn{2}{c}{ Amb. -15 d. } & \multicolumn{2}{c}{ Est. -15 d. } & \multicolumn{2}{c}{ Amb. -30 d. } & Est. -30 d. \\
\hline \multicolumn{1}{c}{ Descritores } & $\mathrm{A}$ & $\mathrm{L}$ & $\mathrm{A}$ & $\mathrm{L}$ & $\mathrm{A}$ & $\mathrm{L}$ & $\mathrm{A}$ & $\mathrm{L}$ & $\mathrm{A}$ & $\mathrm{L}$ \\
\hline Tangerina & $\mathrm{X}$ & $\mathrm{X}$ & $\mathrm{X}$ & $\mathrm{X}$ & $\mathrm{X}$ & $\mathrm{X}$ & $\mathrm{X}$ & $\mathrm{X}$ & $\mathrm{X}$ & $\mathrm{X}$ \\
Laranja Verde & $\mathrm{X}$ & $\mathrm{X}$ & $\mathrm{X}$ & $\mathrm{X}$ & $\mathrm{X}$ & $\mathrm{X}$ & $\mathrm{X}$ & $\mathrm{X}$ & $\mathrm{X}$ & $\mathrm{X}$ \\
Laranja Suco & 5 & 4 & 4 & 4 & 5 & 5 & 3 & 3 & 4 & 3 \\
Laranja Fresca & 5 & 5 & 4 & 5 & 5 & 5 & 3 & 3 & 2 & 3 \\
Albedo & 5 & 6 & 4 & 5 & 4 & 5 & 6 & 4 & 5 & 6 \\
Ácido & $\mathrm{X}$ & $\mathrm{X}$ & $\mathrm{X}$ & $\mathrm{X}$ & $\mathrm{X}$ & $\mathrm{X}$ & $\mathrm{X}$ & $\mathrm{X}$ & $\mathrm{X}$ & $\mathrm{X}$ \\
Frutal & 6 & 5 & 4 & 5 & 4 & 5 & 2 & 2 & 3 & 3 \\
Laranja Madura/Cozida & 5 & 4 & 4 & 4 & 4 & 4 & 5 & 4 & 5 & 4 \\
Floral & $\mathrm{X}$ & $\mathrm{X}$ & $\mathrm{X}$ & $\mathrm{X}$ & $\mathrm{X}$ & $\mathrm{X}$ & $\mathrm{X}$ & $\mathrm{X}$ & $\mathrm{X}$ & $\mathrm{X}$ \\
Cítrico & $\mathrm{X}$ & $\mathrm{X}$ & $\mathrm{X}$ & $\mathrm{X}$ & $\mathrm{X}$ & $\mathrm{X}$ & $\mathrm{X}$ & $\mathrm{X}$ & $\mathrm{X}$ & $\mathrm{X}$ \\
Laranja Oxidada & $\mathrm{X}$ & $\mathrm{X}$ & 2 & 2 & 1 & 1 & 4 & 2 & 3 & 3 \\
Aldeído Casca & 5 & 6 & 6 & 5 & 5 & 5 & 6 & 5 & 6 & 6 \\
\hline
\end{tabular}

Tabela 3 - Comparativo dos descritores das análises do pó, 45 a 75 dias

\begin{tabular}{lcccccccccccccc}
\hline \multicolumn{1}{c}{ Temperatura } & Amb. -45 d. & \multicolumn{2}{c}{ Est. -45 d. } & \multicolumn{2}{c}{ Amb. -60 d. } & \multicolumn{2}{c}{ Est. -60 d. } & \multicolumn{2}{c}{ Amb. -75 d. } & \multicolumn{2}{c}{ Est. -75 d. } \\
\hline \multicolumn{1}{c}{ Descritores } & A & L & A & L & A & L & A & L & A & L & A & L \\
\hline Tangerina & $\mathrm{X}$ & $\mathrm{X}$ & $\mathrm{X}$ & $\mathrm{X}$ & 1 & 2 & 1 & 1 & 1 & 2 & 2 & 2 \\
Laranja Verde & $\mathrm{X}$ & $\mathrm{X}$ & $\mathrm{X}$ & $\mathrm{X}$ & 2 & 1 & 1 & 1 & 2 & 1 & 2 & 2 \\
Laranja Suco & 2 & 2 & 3 & 3 & 1 & 2 & 2 & 1 & 1 & 1 & 4 & 2 \\
Laranja Fresca & 2 & 2 & 2 & 2 & 1 & 1 & 1 & 2 & 1 & 1 & 4 & 2 \\
Albedo & 4 & 5 & 6 & 5 & 6 & 4 & 5 & 4 & 4 & 4 & 5 & 4 \\
Ácido & 1 & 2 & 2 & 2 & 4 & 3 & 3 & 2 & 5 & 4 & 5 & 4 \\
Frutal & 2 & 2 & 3 & 3 & 2 & 2 & 3 & 2 & 2 & 4 & 3 & 3 \\
Laranja Madura/Cozida & 5 & 5 & 4 & 5 & 4 & 5 & 4 & 4 & 4 & 5 & 4 & 4 \\
Floral & 2 & 1 & 1 & 1 & 2 & 3 & 2 & 2 & 3 & 4 & 5 & 3 \\
Cítrico & 2 & 2 & 3 & 3 & 3 & 3 & 5 & 6 & 3 & 4 & 5 & 5 \\
Laranja Oxidada & 6 & 4 & 5 & 4 & 7 & 5 & 6 & 6 & 8 & 8 & 6 & 7 \\
Aldeído Casca & 5 & 6 & 5 & 5 & 6 & 6 & 5 & 5 & 5 & 8 & 5 & 6 \\
\hline
\end{tabular}

As Tabelas 4 e 5 representam os resultados das análises físico-químicas realizadas nas amostras de fase oleosa e de produto final, respectivamente. Pode-se verificar que os resultados correspondem ao período inicial e final, para a fase oleosa e a coletas durante um intervalo de 10 semanas, para o pó.

O índice de refração médio da fase oleosa foi de 1,47, variando ligeiramente entre o início do teste e após o período de armazenamento. A densidade média foi de $0,855 \mathrm{~g} / \mathrm{mL}$, ocorrendo também ligeira variação ao longo do teste. $\mathrm{O}$ pH da solução do pó iniciou em 3,85 e terminou em 4,02 para a amostra em estufa e em 4,07 para a amostra em temperatura 
ambiente. $\mathrm{O}$ aumento nos valores de $\mathrm{pH}$ está relacionado à oxidação das amostra e produção de novos compostos com caráter mais básico, provocando o aumento do $\mathrm{pH}$.

Tabela 4 - Resultados físico-químicos da fase oleosa

\begin{tabular}{cccc}
\hline Temperatura & Ambiente - Início & Estufa -75 dias & Ambiente -75 dias \\
\hline Índice de refração & 1,4726 & 1,4727 & 1,473 \\
Densidade $(\mathrm{g} / \mathrm{mL})$ & 0,8552 & 0,8568 & 0,8553 \\
\hline
\end{tabular}

Tabela 5 - Resultados físico-químicos do pó

\begin{tabular}{lcccc}
\hline \multirow{2}{*}{ Período } & \multicolumn{2}{c}{$\mathrm{pH}($ sol. 1\%) } & \multicolumn{2}{c}{ Umidade } \\
\cline { 2 - 5 } & Estufa & Ambiente & Estufa & Ambiente \\
\hline Início & 3,85 & 3,85 & $3,66 \%$ & $3,66 \%$ \\
15 dias & 3,87 & 3,89 & $3,21 \%$ & $3,79 \%$ \\
30 dias & 3,91 & 3,92 & $3,22 \%$ & $3,98 \%$ \\
45 dias & 3,96 & 3,98 & $3,25 \%$ & $4,19 \%$ \\
60 dias & 3,99 & 4,01 & $3,28 \%$ & $4,31 \%$ \\
75 dias & 4,02 & 4,07 & $3,30 \%$ & $4,44 \%$ \\
\hline
\end{tabular}

A umidade teve o valor de $3,66 \%$ no início dos testes e terminou em 4,44\%, para a amostra em temperatura ambiente e 3,30\%, para a amostra em estufa. A diminuição da umidade da amostra em estufa indica que a temperatura mais elevada provocou perda de umidade ou de compostos voláteis, pois na determinação de umidade, há perda de compostos voláteis por evaporação, sendo a massa desses compostos evaporados computados como umidade. Em contrapartida, a umidade da amostra em temperatura ambiente aumentou ao longo do período de armazenamento.

O acompanhamento dos dados físico-químicos ao longo da vida útil foi satisfatório, pois poucas alterações ocorreram, indicando que a possível deterioração das amostras esteve dentro do esperado, já que a vida útil para esse tipo de produto é de seis meses. Os cromatogramas mostrados nas Figuras 1, 2 e 3 indicam pouca variação no perfil dos terpenos, no período analisado, para o óleo de laranja, os quais são indicativos de oxidação. Os dados apresentados correspondem a um período de quinze dias de armazenamento e confirmam as observações dos provadores da análise sensorial para o período. As corridas cromatográficas ao longo de todo o período de armazenamento não puderam ser obtidas, a fim de confirmar a alteração no perfil dos terpenos concomitantemente à análise sensorial, devido a impossibilidades técnicas (troca da coluna do equipamento), porém as alterações subjetivas advindas da oxidação foram notadas pelos provadores. 


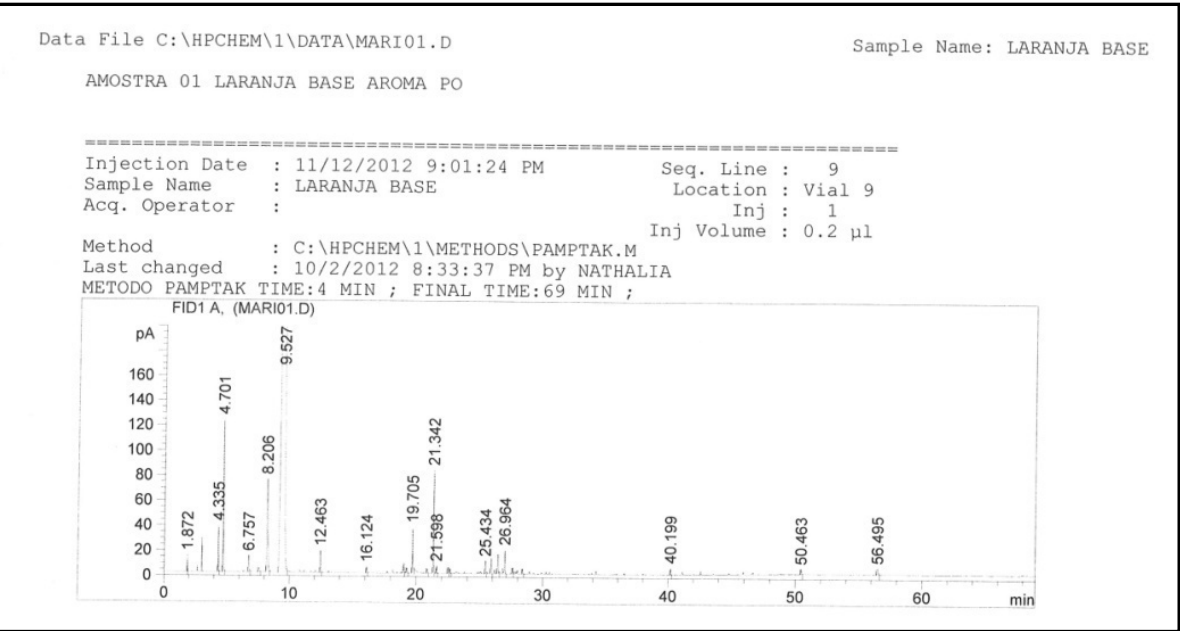

Figura 1 - Perfil cromatográfico do óleo no período inicial.

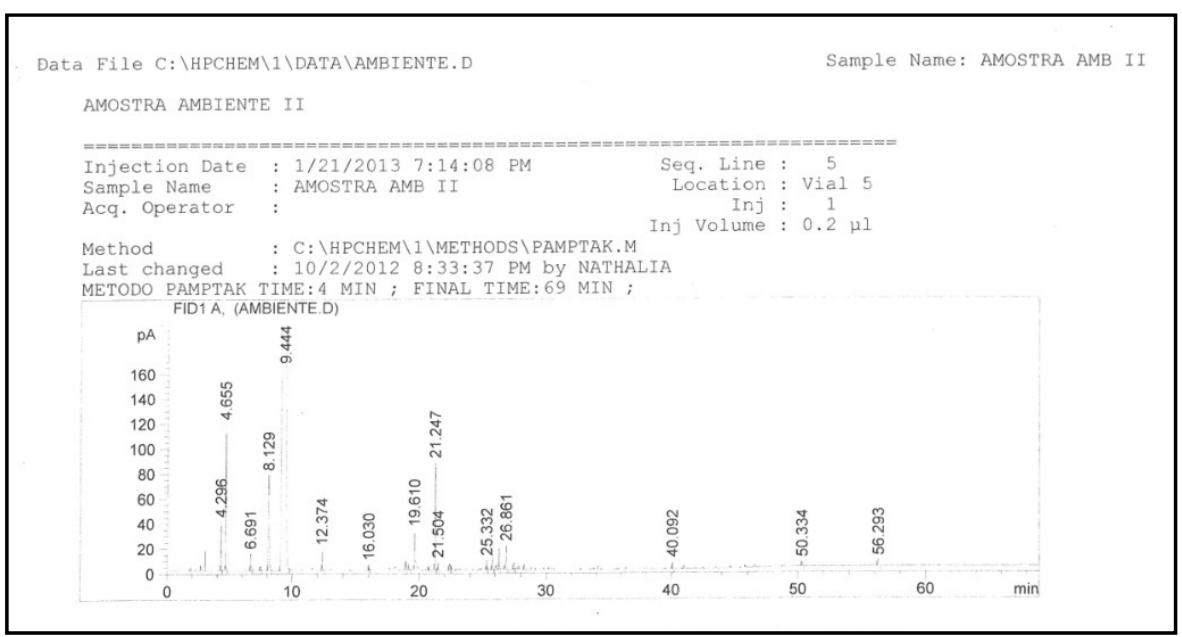

Figura 2 - Perfil cromatográfico do óleo exposto à temperatura ambiente após 15 dias.

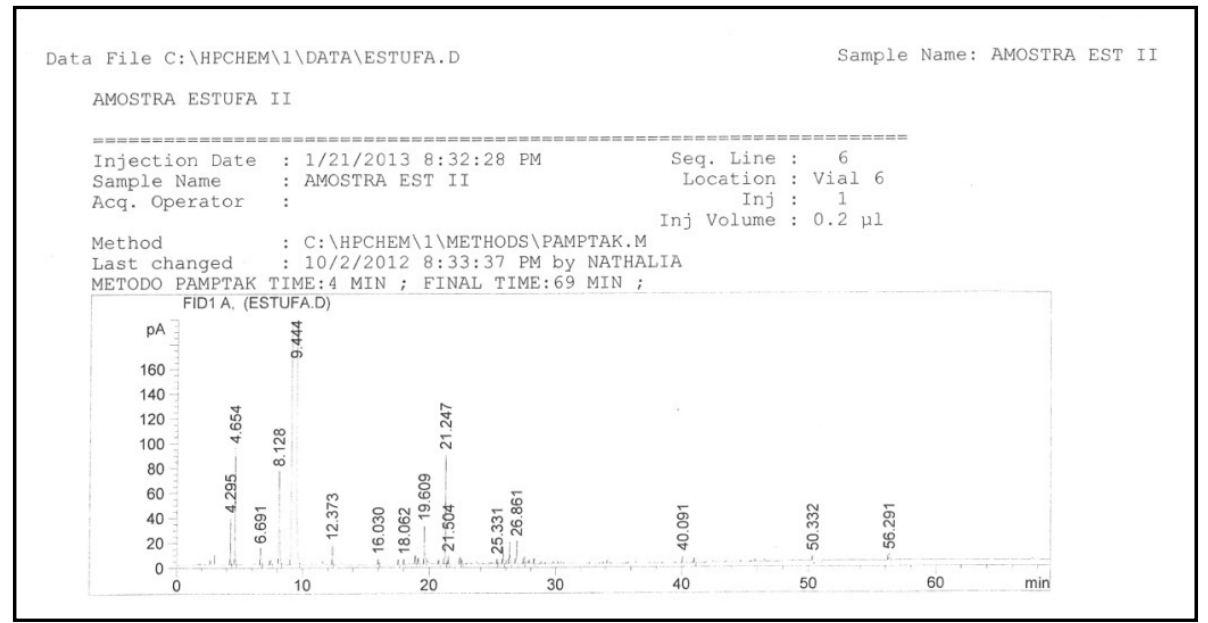

Figura 3 - Perfil cromatográfico do óleo exposto à estufa após 15 dias. 


\section{CONCLUSÃO}

Após estudo de vida útil de um aroma microencapsulado comparado com sua fase oleosa, foi possível perceber, sensorialmente, perdas aromáticas e alterações em sua composição pelo aromista e pelo provador leigo. Essas alterações são caracterizadas pelo aumento da quantidade de terpenos que, por sua vez, permitem verificar o grau de oxidação da amostra. Apesar de o cromatograma não ter indicado variações nas áreas identificadas como terpenos que levassem a conclusão de que havia oxidação na amostra, devido ao período de realização da análise, essa característica foi notada pelas análises sensoriais. A fase oleosa sofreu uma maior alteração aromática durante o período do experimento.

Diante da exposição deste cenário, aliado aos dados físico-químicos obtidos, é possível chegar à conclusão de que o processo de microencapsulação pelo método de spray drying aumenta a vida útil do aroma, permitindo maior distribuição e aplicabilidade do aroma na indústria de alimentos.

\section{REFERÊNCIAS}

ABURTO, L. C.; TAVARES, D. Q.; MARTUCCI, E. T. Microencapsulação de óleo essencial de laranja. Ciênc. Tecnol. Aliment., v. 18, n. 1, p. 45-48, 1998.

AHN, J.-H.; KIM, Y.-P.; LEE, Y.-M.; SEO, E.-M.; LEE, K.-W.; KIM, H.-S. Optimization of microencapsulation of seed oil by response surface methodology. Food Chem., v. 107, p. 98-105, 2008.

CASTELO BRANCO, L. S. Estudo da ampliação de escala na produção de biomassa de Rhodotorula sp. CNPAT02 em processo batelada para obtenção de carotenóides. 2010. 60 f. Dissertação (Mestrado em Engenharia Química) - Universidade Federal do Ceará, Ceará. 2010.

FRASCARELI, E. C.; SILVA, V. M.; TONON, R. V.; HUBINGER, M. D. Effect of process conditions on the microencapsulation of coffee oil by spray drying. Food Bioproducts Process. v. 90, p. 413-424, 2012.

JUN-XIA, X.; HAI-YAN, Y.; JIAN, Y. Microencapsulation of sweet orange oil by complex coacervation with soybean protein isolate/gum Arabic. Food Chem., v. 125, p. 12671272, 2011.

LIU, K.; XU, Y.; WANG, X. Microencapsulation of sweet orange oil terpeneless using the orifice method. J. Food. Eng., v. 110, p. 390-394, 2012.

TONON, R. V.; GROSSO, C. R. F.; HUBINGER, M. D. Influence of emulsion composition and inlet air temperature on the microencapsulation of flaxseed oil by spray drying. Food Res. Int., v. 44, p. 282-289, 2011. 